\title{
IDENTIDADE TERRITORIAL NAS FESTIVIDADES GERMÂNICAS NO SUL DO BRASIL
}

\section{TERRITORIAL IDENTITY IN GERMANIC FESTIVALS IN THE SOUTH OF BRAZIL}

\author{
Cristiano Nicolini \\ Universidade da Beira Interior - Covilhã - Portugal \\ Ângela Cristina Trevisan Felippi \\ Universidade de Santa Cruz do Sul - RS - Brasil
}

\begin{abstract}
Resumo: O artigo traz uma descrição analítica de uma pesquisa etnográfica sobre a quadragésima sétima edição do Festival do Chucrute, uma festa de representação, que ocorre desde 1966 no Vale do Taquari, no Estado do Rio Grande do Sul - Brasil. Esse festival se caracteriza pela valorização das chamadas heranças culturais do território onde se situa, associando-as à imigração germânica que ocorreu no final do século XIX e início do século XX. A pesquisa teve como referencial teórico os estudos culturais para compreender o processo de construção da identidade territorial por meio das ações dos atores locais e das suas manifestações culturais. $O$ artigo estabelece relações entre 0 teórico e a prática social, oferecendo subsídios para se compreender como os territórios se marcam culturalmente por meio de estratégias que passam pela organização de suas manifestações culturais, sendo estas resultado de disputas e acordos simbólicos estabelecidos entre seus agentes.

Palavras-chave: Identidade territorial. Representação. Germanidade. Etnografia. Estudos Culturais.
\end{abstract}

Abstract: This article gives an analytical description of an ethnographic research about the Festival do Chucrute (Sauerkraut Festival)'s $47^{\text {th }}$ edition, which takes place in the Taquari River Valley, in the State of Rio Grande do Sul, every year since 1966. This festival highlights the cultural heritage of the region paying tribute to the German immigration occurred at the end of the $19^{\text {th }}$ and beginning of the 20th centuries. The research is based on cultural studies as a theoretical reference to understand the process of constructing territorial identity through the action of local actors and their cultural expressions. The article establishes relationships between theory and social practice, providing elements to understand how territories are culturally self-labeled using strategies that include the organization of their cultural expressions, which result from disputes and symbolic agreements between their agents.

Keywords: Territorial identity. Representation. Germanness. Ethnography. Cultural studies.

Introdução

Considerando que "[...] a festa é uma produção do cotidiano, uma ação coletiva, que se dá num tempo e lugar definido e especial, [...] cujo produto principal é a simbolização da unidade dos participantes na esfera de uma determinada identidade" (GUARINELLO, 2001, p. 972), é possível enxergar, nesse cenário, possibilidades de investigação a partir de diversas áreas de conhecimento, entre elas as ciências sociais. Tendo em vista que as festas típicas inspiradas na etnicidade estão presentes em diversos territórios, cabe aos pesquisadores desse campo do conhecimento analisar tais momentos de produção cultural para 
compreender o processo de construção de identidades culturais regionais no contexto da globalização.

A identidade cultural é uma construção dos sujeitos que se dá por meio dos processos sociais (HALL, 2006). Se fosse inata, ela não precisaria ser evocada, evidenciada e narrada. A luta pela afirmação identitária emerge sempre que há alguma dúvida ou incerteza. Esse esforço por evidenciar determinada identidade cultural pode ser percebido em diferentes tempos e lugares, na medida em que as pessoas buscam pelos referenciais históricos que sustentem o discurso que pretendem afirmar.

No entanto, vivemos um processo em que essas identidades, antes coesas e duradouras, hoje estão "(...) entrando em colapso, como resultado de mudanças estruturais e institucionais. O próprio processo de identificação, através do qual nos projetamos em nossas identidades culturais, tornou-se mais provisório, variável e problemático." (HALL, 2006, p. 12).

As identidades se constroem, historicamente, por meio de representações sociais ou culturais. "A representação, compreendida como um processo cultural, estabelece identidades individuais e coletivas e os sistemas simbólicos nos quais ela se baseia fornecem possíveis respostas às questões: quem eu sou? O que eu poderia ser? Quem eu quero ser?" (WOODWARD, 2000, p. 17).

É dessa forma, a partir da construção de símbolos, que as identidades vão se definindo na sociedade, a partir de referências que as tornem legítimas frente ao percurso da história. Esse processo se dá pelo estabelecimento da diferença, de forma relacional, dependente. "Essa marcação da diferença ocorre tanto por meio de sistemas simbólicos de representação quanto por meio de formas de exclusão social." (WOODWARD, 2000, p. 39).

Partindo dessa perspectiva sobre a identidade cultural, é indispensável compreender a sua função na formação histórico-social das diferentes regiões que compõem o planeta. Somente a partir desse referencial é possível identificar as origens e os significados dos elementos que constituem as paisagens construídas pelos atores locais.

A identidade cultural representa o conjunto de crenças, valores, hábitos, práticas e demais manifestações que caracterizam as regiões. No entanto, não é mais compreendida numa perspectiva essencialista, segundo a qual a identidade era adquirida naturalmente pelos sujeitos, mas, sim, como construção cultural feita a partir do vivido pelos distintos grupos sociais.

Os diferentes territórios, por sua vez, são formados por essas representações do imaginário das pessoas que neles vivem, constituindo, assim, as chamadas identidades territoriais. Por meio de simbologias e materializações desse imaginário, cada território busca afirmar a sua identidade cultural, elegendo elementos que possam vir a fortalecer a sua posição frente aos movimentos incertos da globalização.

Mais do que nunca, as múltiplas identidades e os múltiplos territórios investem na diferenciação, tentando sobreviver num contexto em que a padronização cultural pode representar uma ameaça. Para isso, são criadas as 
tradições, que ligam o presente a um passado cheio de mitos e de narrativas imaginadas a partir de processos históricos muitas vezes diferentes daquilo que se conta.

A partir dessas considerações, o presente artigo propõe uma descrição analítica de um estudo etnográfico realizado num festival de cultura germânica, no interior do Estado do Rio Grande do Sul - Brasil. O estudo buscou compreender a construção da identidade territorial no Vale do Taquari ${ }^{1}$ por meio do $47^{\circ}$ Festival do Chucrute $^{2}$, realizado nessa região, no Município de Estrela, sendo uma das mais tradicionais manifestações culturais presentes nessa região.

O Festival surgiu em 1966, representando uma festividade da Comunidade Luterana, da Igreja Evangélica de Confissão Luterana do Brasil (IECLB) local, que, em seu período inicial, envolvia apenas integrantes da Igreja, em sua maioria descendentes de imigrantes alemães.

Com o passar dos anos, o evento se consolidou no Município de Estrela e na região, complexificou-se em termos de construção de identidade cultural e passou a marcar um espaço no que tange à identidade territorial. Atualmente, reúne visitantes do Vale do Taquari e de outras regiões do Rio Grande do Sul. Ocorre em dois finais de semana com jantares e bailes e uma programação que recheia o período, basicamente com apresentações de danças folclóricas e eventos gastronômicos.

Acompanhou-se a realização da produção e da realização da festa durante os meses de março, abril e maio de 2012, num estudo etnográfico, compreendido como aquele que permite entender a cultura das diferentes sociedades a partir de levantamentos acerca das crenças, valores, desejos e comportamentos humanos originários de suas próprias vivências. Ainda, pela observação direta e por um período de tempo, a etnografia possibilita observar as formas costumeiras de viver de um grupo particular de pessoas, um grupo de pessoas associadas de alguma maneira, uma unidade social representativa para estudo, seja ela formada por poucos ou muitos elementos (MATTOS, 2001).

Para o estudo de campo, foram acompanhados os momentos de preparação da festa (reuniões e encontros para produção do material de divulgação, preparação dos alimentos a serem servidos no Festivale a organização do espaço físico para o evento) e a festa em si, buscando-se visualizar o evento em sua totalidade.

As técnicas de coleta de dados foram a observação dos momentos de preparação e ocorrência da festa, a produção de registros fotográficos, a entrevista

\footnotetext{
1 A região do Vale do Taquari se localiza no centro-leste do Rio Grande do Sul. Inicialmente povoada por indígenas, a atual região foi sucessivamente sendo ocupada por outros grupos étnicos desde o século XVII, dentre os quais se destacam os portugueses, africanos e açorianos, até o século XVIII. No século XIX, os imigrantes alemães e italianos passaram a ocupar as terras altas e baixas dos atuais 36 municípios que compõem a região, boa parte deles resultados de emancipações dos municípios de Lajeado e de Estrela.

2 "Chucrute é repolho fermentado naturalmente, com condimentos [...].O chucrute, hoje, é consumido em praticamente toda a Europa e no Brasil, onde identifica-se naturalmente como acompanhamento de pratos de origem alemã" (Fonte: Site oficial do Festival do Chucrute. Disponível em: <http://www.festivaldochucrute.com.br>. Acesso em: 3 nov. 2012
} 
com os organizadores e com os participantes ${ }^{3}$ e a pesquisa documental junto ao acervo da IECLB e em registros historiográficos locais.

A etnografia envolveu o acompanhamento de reuniões preparatórias e os eventos de lançamento, de sensibilização para a festa e a programação do Festival do Chucrute, assim organizados:

(1) 13 de abril - lançamento do Festival, no Salão da OASE;

(2) $1^{\circ}$ de maio - divulgação do Festival no pórtico de entrada de Estrela, com entrega de brindes, folders e adesivos;

(3) 5 de maio - tradicional Grande Desfile Típico dos grupos folclóricos com carros alegóricos, som e banda pelas ruas de Estrela e Lajeado;

(4) 19 de maio - $1^{\circ}$ Baile Típico com decoração característica, jantar com comida típica da culinária dos imigrantes germânicos e cerveja, bem como a apresentação dos Grupos de Danças Folclóricas Alemãs de Estrela', compostos por mais de 450 dançarinos, no Centro Comunitário Cristo Rei;

(5) 20 de maio - Café Colonial e apresentação dos Grupos de Danças Folclóricas Alemãs de Estrela, no Centro Comunitário Cristo Rei;

(6) 21 de maio - $6^{a}$ Festa das APAEs, com apresentação de danças folclóricas, no Centro Comunitário Cristo Rei;

(7) 23 de maio - 19a Festa do Idoso, com apresentação de grupos de danças do Vale do Taquari convidados e, ao meio-dia, almoço típico da culinária dos imigrantes e, à tarde, o Baile do Idoso, no Centro Comunitário Cristo Rei;

(8) 24 de maio - Festa da OASE - 100 anos, no Salão da OASE, junto à Comunidade Evangélica de Estrela;

(9) 26 de maio - $2^{\circ}$ Baile Típico, com decoração característica, jantar com comida típica e cerveja, bem como a apresentação dos Grupos de Danças Folclóricas Alemãs de Estrela, composto por mais de 450 dançarinos, no Centro Comunitário Cristo Rei;

(10) 27 de maio - encontro e apresentação de grupos de danças folclóricas de outros municípios, com Café da Tarde, no Centro Comunitário Cristo Rei.

Sendo assim, a festividade foi tomada como objeto de análise para a compreensão da atuação do evento no referido processo de construção de identidade territorial. Em meio a uma série de estratégias para evidenciar as particularidades e potencialidades desse território, o Festival do Chucrute representa um interessante campo de observação para captar as manifestações

\footnotetext{
${ }^{3}$ Ao longo da pesquisa foram realizadas entrevistas formais e informais com organizadores do Festival, membros da Ordem Auxiliadora das Senhoras Evangélicas (organização ligada a Igreja Luterana e que participa ativamente da realização do Festivah, organizadores e participantes das festividades, autoridades de Estrela. O conteúdo das entrevistas não é usado de forma literal neste artigo, portanto, não serão feitas referências diretas a uma ou outra entrevista em particular.

${ }^{4}$ Os Grupos...é uma organização ligada a Igreja Evangélica de Confissão Luterana do Brasil, integrada por vários grupos de danças germânicas, que se apresentam no Festival do Chucrute, assim como em outras festividades
} 
culturais da região, na medida em que os atores locais interagem na elaboração de estratégias de diferenciação regional no contexto da globalização.

\section{Uma festa de representação}

Ao se tratar de construção de identidade territorial a partir das manifestações culturais num dado espaço, tem-se presente que o que está em discussão são disputas de interesses e de sentidos sobre o espaço. "O território também pode ser entendido como uma imagem, como uma construção social simbólica, que é alimentada e alimenta uma rede de relações sociais não restritas a uma espacialidade contínua e delimitada fisicamente." (CARNEIRO, 2008, p. 72).

Nessa linha, a região do Vale do Taquari é, portanto, um território em disputa. A região teve distintas formações humanas, que povoaram o espaço em diferentes momentos históricos, sobrepondo-se umas às outras, ao longo dos últimos 200 anos. Desse processo, prevalecem três grandes representações étnicas: açorianos, germânicos e italianos, frutos de lutas simbólicas em que os atores sociais elegeram determinadas representações no decorrer de sua história.

$\mathrm{Na}$ configuração identitária do Vale do Taquari, a cultura desses três povos de imigrantes colonizadores foi sendo incorporada como os principais referenciais identitários dos municípios que se formaram ao longo do século XX. Hoje, os 36 municípios que compõem a região investem na promoção de uma determinada identidade, a qual se concretiza por meio de projetos gerenciados pelas iniciativas pública e privada. Ainda dentro dessa prevalência há, dentre as três identidades mencionadas, a hegemonia das representações associadas à germanidade, em contraposição a outros referenciais identitários regionais.

O Festival do Chucrute emerge desse cenário histórico, em que atores sociais o elaboraram em um determinado contexto - a comunidade luterana do Município de Estrela - e, com o passar dos anos, o projetaram para além dos limites municipais, transformando-o num evento e numa marca regional associada a um território.

A partir de sua primeira edição, o evento foi se adaptando às diferentes conjunturas históricas. Surgiu como um baile comunitário, que agregava um número limitado de pessoas, e, no decorrer de quase cinco décadas, passou a representar uma das mais destacadas festividades do calendário regional, integrando, inclusive, a lista de eventos oficiais da Secretaria de Turismo do Rio Grande do Sul (Fonte: <www.turismo.rs.gov.br.> Acesso em: 2 nov. 2012).

Considerando o Festival do Chucrute como uma festa de representação, nesta pesquisa etnográfica levou-se em consideração o que Amaral (2000, p. 4) afirma sobre este tema:

$\mathrm{Na}$ categoria das Festas de Representação, contam-se aquelas que apresentam "atores" e "espectadores". Os atores, que podem ser em número restrito, participam diretamente da festa organizada para os espectadores que participam indiretamente do evento ao qual atribuem, 
entretanto, uma dada significação e pela qual são mais ou menos afetados. O elemento importante é que os participantes são em número limitado enquanto os espectadores são muito numerosos, especialmente hoje, com as reportagens diretas via televisão. É preciso sublinhar que os espectadores e os atores são conscientes das "regras do jogo" (ritos, cerimônias e símbolos), mas que eles "percebem" o evento de modo diferente conforme o papel que lhes é atribuído.

De acordo com depoimentos de atores locais, documentos disponíveis no acervo da IECLB de Estrela e bibliografias regionais (SCHIERHOLT, 2002; HESSEL, 1983), a história do Festival do Chucrute teve início no ano de 1966, quando ainda era denominado Baile do Chucrute. A partir daquela data, o evento foi adquirindo proporções cada vez maiores, transformando-se em festival alguns anos depois, quando se passou a realizar dois bailes, um antes e outro após o aniversário de emancipação política de Estrela.

Durante quase meio século de existência, muitos elementos da festividade se modificaram, apesar dos organizadores ressaltarem a continuidade e a manutenção das tradições que caracterizam essa manifestação cultural ${ }^{5}$.

Conforme relatam membros da IECLB do município, na década de 1960, portanto, o então Baile do Chucrute ainda não possuía a dimensão que assumiu na atualidade. Era uma festividade voltada basicamente para os membros da Comunidade Evangélica de Estrela (IECLB), sendo que era realizado no Ginásio Esportivo da Sociedade Ginástica de Estrela (SOGES), comportando um público numericamente inferior àquele que hoje prestigia o evento.

Em maio de 2005, o Jornal Folha de Estrela publicou um suplemento especial sobre os 40 anos do Festival. No editorial, o articulista destacou: "O Festival do Chucrute [...], há quatro décadas, encanta os estrelenses, seus vizinhos e todos aqueles que aqui aportam no mês de maio, para conhecer a nossa mais tradicional forma de cultuar as tradições de alegria dos nossos antepassados, vindos da Alemanha há mais de 180 anos" (2005, p. 2).

A partir de relatos e leituras acerca do evento, pode-se perceber que, como toda festa dessa natureza, associada a uma herança cultural, o Festival do Chucrute foi incorporando elementos que auxiliaram na sua consolidação como portador de um discurso identitário. Para isso, seus organizadores e incentivadores investiram na criação de símbolos que o identificassem com a cultura germânica (alimentos e vestimentas trazidos ao Brasil pelos imigrantes e adaptados em seu uso, artefatos nas cores da bandeira da Alemanha, músicas folclóricas germânicas, dentre outros).

Essas representações simbólicas se materializaram nos cartazes, folders, adesivos e demais panfletos de divulgação, decoração dos espaços, vestimentas

\footnotetext{
${ }^{5}$ Em entrevista realizada com casais comendadores do $47^{\circ}$ Festival do Chucrute, os integrantes evidenciaram a manutenção das tradições na realização do evento. Por exemplo, na confecção das guirlandas que decoram o salão dos bailes, ainda se utiliza o cipreste natural, apesar de alguns membros mais jovens da Comenda desejarem substituir por material sintético, em função da praticidade.
} 
dos organizadores e dançarinos durante o Festival e em outros meios de afirmação de marcas culturais. Dentre os símbolos, merecem destaque os bonecos Chuck $e$ Ruth, que, a partir da festa, foram apropriados como mascotes do Município de Estrela.

\section{Ilustração 1. Mascotes do Festival do Chucrute e de Estrela - Chuck e Ruth}



Fonte: Fotografia do autor, 1\%/05/2012.

Os bonecos símbolo aparecem em diversos materiais publicitários da festa e acabam sinalizando um discurso identitário que extrapola esse limite espacial da festa e do município que a sedia, personificando a identidade cultural que se pretende evidenciar no território do Vale do Taquari.

Evidentemente, essa identidade territorial é articulada em outros espaços dos demais municípios, como nas práticas sociais dos sujeitos dentro das instituições (escolas, igrejas, governos municipais, entidades associativas). O Festival do Chucrute é um dos espaços mais significativos nesse território, pela permanência no tempo, pela abrangência espacial em termos de público e pela adesão dos diferentes atores do município que o produz.

Esta participação se torna evidente desde os primeiros preparativos, ainda no mês de março, até a culminância do evento no mês de maio. O município vai recebendo sinalizações anunciando que o Festival se aproxima, sendo que a primeira divulgação se dá por meio de flâmulas expostas nas principais ruas da cidade.

A $47^{a}$ edição do Festival do Chucrute ocorreu de 19 a 27 de maio de 2012, no salão do Centro Comunitário Cristo Rei, localizado no Bairro Cristo Rei, em Estrela. Apesar de ser organizado e realizado pela IECLB do município, o evento ocorre no salão da Comunidade Católica, pois a primeira não possui instalações com as proporções necessárias para a realização dos bailes e demais atividades que compõem o evento. 


\section{Traduções culturais}

Os estudos culturais são referenciais para compreender a função dessas manifestações culturais na sociedade. De acordo com Escosteguy (2001, p. 43), esse campo teórico oferece a possibilidade de analisar essa dinâmica de comunicação numa perspectiva "[...] interdisciplinar que entende os processos culturais como interdependentes e não como fenômeno isolado, como é a prática usual da maioria das disciplinas".

A partir dos estudos culturais, pode-se compreender a história do Festival do Chucrute como um processo cultural conectado à estrutura social em que se insere e ao processo produtivo como um todo, tendo em vista que o evento divulga o município e a região onde está inserido, mobiliza diferentes atores (incluindo os da esfera política institucional e econômica) e movimenta a economia do município ao atrair visitantes para a festividade.

Os atores locais ou regionais que participam desse processo são os responsáveis pela perpetuação dessa manifestação cultural, pois reconhecem a sua importância para o território no qual atuam. Mesmo que para muitos o Festival represente tão somente uma oportunidade de expressar valores e tradições culturais, o evento acaba interagindo com as esferas da economia e da política do lugar no qual é produzido.

Tabela 1. Resultados e números do $47^{\circ}$ Festival do Chucrute

\begin{tabular}{|l|l|l|l|}
\hline $\begin{array}{l}\text { Bailes do } \\
47^{\circ} \text { Festival do } \\
\text { Chucrute }\end{array}$ & $\begin{array}{l}\text { Refeições } \\
\text { servidas }\end{array}$ & $\begin{array}{l}\text { Público } \\
\text { presente }\end{array}$ & $\begin{array}{l}\text { Total } \\
\text { em Reais (R\$) } \\
\text { movimentado }\end{array}$ \\
\hline $\begin{array}{l}1^{\circ} \text { Baile } \\
(19 / 05 / 2012)\end{array}$ & 1135 & 2400 & - \\
\hline $\begin{array}{l}2^{\circ} \text { Baile } \\
(26 / 05 / 2012)\end{array}$ & 1447 & 2500 & - \\
\hline Total: & 2582 & 4900 & $84.912,78$ \\
\hline
\end{tabular}

Fonte: Secretaria da IECLB de Estrela. Elaboração gráfica dos autores, 2012.

Quando se observa a preparação e a execução de uma festividade inspirada na etnicidade, ficam evidentes as intenções daqueles que agem na elaboração das diferentes etapas desse processo. São pessoas que interagem com símbolos do passado, mas que são reelaborados no presente. Os preparativos revelam os referenciais dos atores que participam dessa criação coletiva, os quais buscam legitimar elementos considerados tradicionais. $\mathrm{Na}$ análise das situações observadas, considerou-se a seguinte proposição: 
retoma o passado como causa social ou precedente estético; ela renova o passado, refigurando-o como um 'entre-lugar' contingente, que inova e interrompe a atuação do presente. O 'passado-presente' torna-se parte da necessidade, e não da nostalgia, de viver (BHABHA, 2001, p. 27).

Essa necessidade de viver a que o autor se refere justifica, em grande parte, a motivação de um grupo de atores sociais no sentido de reconstruir o passado, de elaborar o seu presente a partir de um tempo que já se perdeu, mas que continua servindo de referência às manifestações culturais de hoje. Não há, portanto, nessa prática, uma tentativa de reviver o passado, mas de elaborar espaços de memória cujos artefatos são compostos a partir de representações e idealizações das narrativas vistas e revistas ao longo do tempo.

Nesse caminho entre o passado e o presente, vão se agregando e desprendendo elementos que cada geração, a partir de interesses específicos de cada tempo e lugar, tratam de utilizar ou não nas suas próprias narrativas. $O$ cenário do Festival do Chucrute se configura, assim, como uma dessas reelaborações do passado, em que os atores acreditam manter as tradições do passado, quando já estão atuando como tradutores culturais.

Ilustração 2. Noite do lançamento oficial do $47^{\circ}$ Festival do Chucrute de Estrela

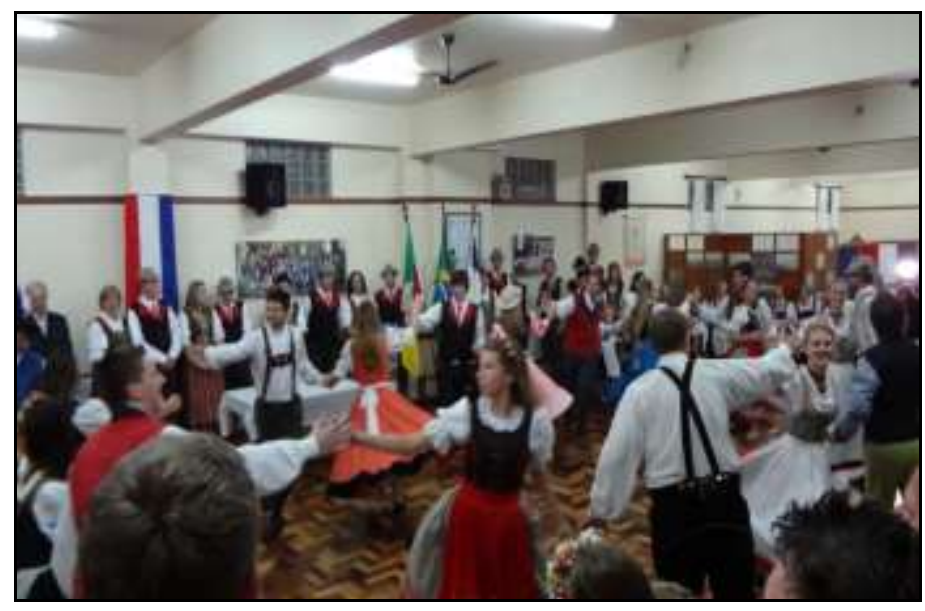

Fonte: Fotografia do autor, 2012.

Ilustração 3. Cartaz de divulgação do $47^{\circ}$ Festival do Chucrute 


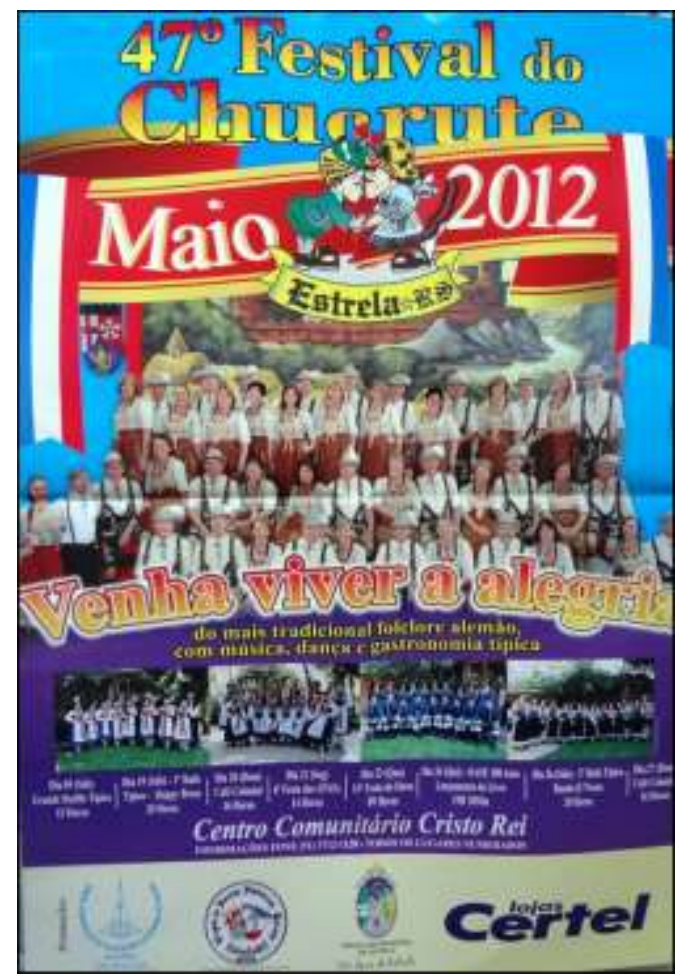

Fonte: IECLB de Estrela, 2012.

Com esses referenciais, partiu-se para o trabalho de campo etnográfico, quando foi possível identificar inúmeras relações estabelecidas entre os participantes da elaboração do $47^{\circ}$ Festival do Chucrute. Apesar de não existir um envolvimento idêntico por parte dos diferentes atores que interagem na organização do evento, todos demonstraram disposição ao participar dessas atividades, denotando um espírito de cooperação e solidariedade entre as pessoas. A espontaneidade com que as diferentes faixas etárias interagiram também foi um aspecto relevante, considerando que, para muitos indivíduos, essas vivências não fazem parte do seu cotidiano.

Nesse caso, pode-se constatar aquilo que Bhabha afirma sobre a invenção de tradições.

O reconhecimento que a tradição outorga é uma forma parcial de identificação. Ao reencenar o passado, este introduz outras temporalidades culturais incomensuráveis na invenção da tradição. Esse processo afasta qualquer acesso imediato a uma identidade original ou a uma tradição 'recebida'. (BHABHA, 2001, p. 21).

De fato, os integrantes que se divertem no festival não são herdeiros de uma identidade legítima, mas participam de um processo de reinvenção de um passado do qual não fizeram parte, e com o qual, em muitos casos, sequer possuem vinculação étnica. São atores sociais que assumem uma função na construção de uma identidade para o território onde vivem, conscientemente ou não.

Como afirmaram os participantes, todo esforço empregado é voluntário, da 
mesma forma que ocorreu na primeira edição do Baile do Chucrute, em 1966. Essa ênfase no caráter comunitário da festividade demonstra a valorização de características identitárias que os envolvidos nessa manifestação cultural buscam evidenciar, apesar das alterações que ocorreram ao longo de quase 50 anos de existência. Como diz Woodward (2000, p. 27), quando se afirma uma identidade, “(...) podemos buscar legitimá-la por referência a um suposto e autêntico passado - possivelmente um passado glorioso, mas, de qualquer forma, um passado que parece 'real' - que poderia validar a identidade que reivindicamos."

Com essa concepção, fez-se a observação dos preparativos das festividades e do Festival em si. Nesse sentido, as impressões dos que participam do evento variam de acordo com as vivências e percepções individuais, mas o ambiente estimulava, à primeira vista, a sensação de uma "viagem imaginária" a algum lugar diferenciado da realidade - o país dos antepassados, a colônia, o interior. Grandes painéis retratavam paisagens da Alemanha, destacando casas em estilo enxaime $\tilde{F}$, montanhas e outros elementos da natureza.

No dia 19 de maio de 2012, realizou-se o primeiro baile do Festival. Chegando ao local, antes do horário de início do evento, pôde-se verificar o cenário preparado ao longo da semana. Na porta de entrada, o casal de mascotes Chuck e Ruth aguardava as pessoas. Os casais comendadores e representantes dos Grupos de Danças Folclóricas Alemãs de Estrela faziam a recepção e davam as boas vindas aos que chegavam. Em seguida, recolhia-se o ingresso, de onde era destacada uma parte em troca de um brinde - um copo de vidro com a logomarca do evento e dos patrocinadores.

A categoria oficial dos Grupos de Danças Folclóricas Alemãs de Estrela deu início às apresentações com uma "coreografia moderna", como anunciou o instrutor Andreas Hamester. Esse grupo de jovens ocupou o espaço central do salão, vestindo o uniforme dos Grupos (azul marinho com o símbolo da entidade). A dança foi bastante diferente das coreografias típicas que costumam apresentar, provocando surpresa no público presente. Ao invés de passos tradicionais das danças folclóricas, os jovens faziam malabarismos e movimentos sob o efeito de luzes coloridas. No final da coreografia, eles tiraram lenços escondidos na roupa e abriram em direção ao público, nos quais estavam destacadas palavras como amizade, respeito, alegria, cultura e folclore.

Em seguida, o orador anunciou que mais de 20 municípios se faziam presentes na noite, por meio de grupos de excursão ou visitantes individuais. Saudou os representantes dos estados do Espírito Santo e de Minas Gerais, bem como dos municípios gaúchos (foram citados 32). Convidou para que todos conhecessem a cerveja artesanal, cuja produção estava sendo demonstrada num local do salão, com degustação e venda de vários tipos da bebida. Também havia outro estande no qual eram confeccionados canecos com a fotografia das pessoas,

\footnotetext{
${ }^{6}$ Estilo de construção de moradias medieval que remete à Alemanha, muito embora não seja exclusivo deste território, usado pelos imigrantes germânicos no Sul do Brasil no período da colonização. Construções antigas com este estilo têm sido recuperadas, bem como novas têm sido construídas para fins turísticos, inclusive em vários municípios do Vale do Taquari, como Westfália, Teutônia, Forquetinha, Lajeado.
} 
tirada na hora. Essas fotografias eram produzidas com o uso de acessórios da indumentária típica dos Grupos de Danças Folclóricas (chapéus, tiaras de flores etc.).

Durante as apresentações, o público foi convidado a se dirigir ao buffet, que foi servido no espaço lateral do salão. Enquanto os dançarinos se revezavam no palco central, as pessoas jantavam nas mesas que circundavam este espaço. $O$ cardápio tinha como prato principal o chucrute - cujo preparo se iniciou no mês de abril -, juntamente com saladas, eisbein (joelho de porco), salsicha bock, batata a vapor e carré. Os itens desse cardápio, segundo os organizadores do evento, são inspirados na "culinária dos antepassados alemães". No entanto, outros revelaram que nem todos os alimentos servidos na atualidade são típicos do Festival, sendo que foram incorporados ao longo do tempo.

Após a apresentação da categoria mirim de dançarinos, o instrutor geral anunciou o grupo de danças das mulheres, denominado Caminhando Juntos. As integrantes fazem parte da OASE, e ensaiam as suas coreografias com uma instrutora própria. $\mathrm{Na}$ noite, elas homenagearam os 20 anos de existência dessa categoria, apresentando uma dramatização na qual a Rainha Mirim do $47^{\circ}$ Festival do Chucrute entregou um presente para a integrante mais idosa do grupo, de 86 anos de idade; o presente era uma caixa com flores, as quais foram distribuídas às demais dançarinas da categoria. Em seguida, elas apresentaram uma coreografia inspirada nas danças folclóricas alemãs.

As apresentações continuaram com as demais categorias, formadas por crianças, jovens e adultos. Foram diversas coreografias inspiradas no folclore alemão, cujos dançarinos trocavam os trajes sem que houvesse intervalo entre cada categoria. Alguns saíam às pressas do palco para trocar os figurinos, entrando novamente logo em seguida. Entre os integrantes dos Grupos, percebia-se a concentração e a alegria ao encerrar cada etapa do espetáculo. Alguns comemoravam, outros se abraçavam ou auxiliavam os colegas nos detalhes dos figurinos.

Após essas danças, o instrutor pediu que abrissem mais espaço no centro do salão, pois os dançarinos iriam apresentar uma dramatização, intitulada Lenda da Floresta de Grunenwald, originária de uma região da Alemanha. Os dançarinos entraram com figurinos representando os personagens da lenda, a qual narrava uma história de princesas, reis, bruxas e outros seres míticos da Idade Média europeia.

As últimas danças foram apresentadas pela categoria de casais (coroas) e pelos membros da comenda do $47^{\circ}$ Festival do Chucrute. Os casais comendadores dançaram simbolizando o convite para que todo o público participasse da festa. Nesse momento, todos os integrantes voltaram ao palco e dançaram, de forma entusiasmada, a música Viva a Colônia, fazendo um agradecimento e encerrando o espetáculo dos Grupos de Danças Folclóricas Alemãs de Estrela naquela noite.

Após a finalização das danças, portanto, teve início o baile, quando o público pôde ocupar o centro do salão para dançar ao som de uma banda musical. Inicialmente foram tocadas músicas tradicionais das festas germânicas (bandinhas). Em seguida, outros estilos musicais deram continuidade ao baile, que se estendeu 
até a madrugada.

No dia 20 de maio de 2012, à tarde, foi realizado o tradicional café colonial do Festival do Chucrute. Nesse dia, a entrada para assistir às danças dos Grupos foi um quilo de alimento não perecível, doado a entidades do município. O café colonial foi cobrado de acordo com o peso do prato, sendo servido enquanto os dançarinos repetiam algumas das coreografias apresentadas na noite anterior. Foram servidos doces e salgados variados, acompanhados de chá, café e refrigerantes. Nesse dia, as crianças participaram mais intensamente da festa, sendo que muitas famílias vieram prestigiar o evento.

Ao longo das suas 47 edições, o Festival do Chucrute foi incorporando novas atrações ao seu calendário. Se no início era composto apenas de um baile típico, hoje se estende ao longo de toda uma semana, entre os sábados que antecedem e sucedem o aniversário de emancipação do Município de Estrela (20 de maio).

O segundo baile do $47^{\circ}$ Festival do Chucrute ocorreu no dia 26 de maio de 2012, no mesmo local. A abertura foi feita pelo presidente da IECLB e comendador do evento, Ernani Sehn, que destacou: "Além da boa música, ocorrerá a troca da Comenda, bem como a coroação das rainhas adulta e mirim, que serão responsáveis pela divulgação do $48^{\circ}$ Festival do Chucrute, em 2013."

O funcionamento foi semelhante ao do primeiro baile, sendo que as apresentações dos Grupos de Danças Folclóricas Alemãs de Estrela foram realizadas na mesma sequência. $O$ instrutor destacou, no discurso de abertura, a presença do jornalista Alexandre Garcia, que viveu em Estrela e veio prestigiar o Festival. Lembrou que 412 dançarinos iriam se apresentar na noite, como no baile anterior.

Em seguida, foram apresentadas as danças de todas as categorias. No final, a categoria dos Casais apresentou uma coreografia que representava os bailes de Kerb, lembrando, conforme o instrutor de danças destacou, "[...] a origem dos costumes dos teuto-brasileiros no Rio Grande do Sul, no Vale do Taquari e em Estrela". Os casais entraram em cena vestindo roupas e utilizando acessórios alusivos à vida nas colônias alemãs (trajes de agricultores, que é a representação típica do colono alemão), dramatizando de forma cômica a chegada dos parentes para a festa, a organização da residência, o culto religioso, as refeições, as danças e, finalmente, a despedida dos convidados.

Nessa noite, também se fizeram presentes três grupos de danças folclóricas alemãs vindos da Argentina, convidados pelo instrutor Andreas Hamester (o qual coordena intercâmbios entre os grupos estrelenses e argentinos). Outro aspecto que se destacou no segundo baile foi o grande número de famílias que vieram trajadas com roupas típicas, semelhantes àquelas usadas pelos Grupos de Danças Folclóricas.

Diversos grupos de pessoas, de diferentes locais e diferentes contextos culturais estavam presentes nesse baile. Ao se observar o lugar, foi possível perceber uma multiplicidade de diálogos ocorrendo naquele espaço, a partir das vivências de cada ator social que integrava o cenário da festa. E cada ator, 
pertencendo a outros contextos nos quais atuam em outros momentos, trazia consigo elementos que deram complexidade ao artefato cultural observado a partir da etnografia.

Nesse momento, percebeu-se a dificuldade de captar todos os sinais que os atores transmitiam, todas as suas mensagens verbais e corporais. Os depoimentos, os discursos, as vestimentas, o cenário, a música, o aroma... Nem mesmo todos esses ingredientes reunidos são suficientes para compreender a totalidade do significado do objeto pesquisado.

A festa criada para valorizar e divulgar a cultura alemã no território do Vale do Taquari se transformou numa festa de culturas que se encontram e se comunicam, passando a representar um espaço no qual o hibridismo cultural se torna cada vez mais evidente, apesar dos discursos e das representações buscarem cristalizar esse evento como uma manifestação cultural germânica.

Ilustração 4. Salão decorado para as festividades do $47^{\circ}$ Festival do Chucrute

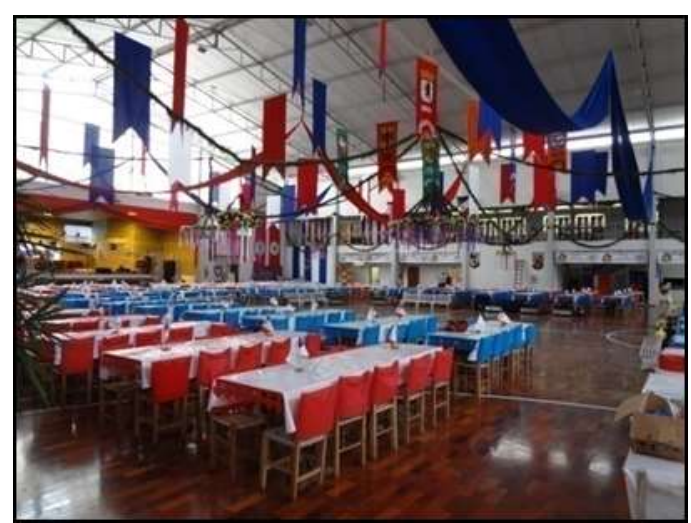

Fonte: Fotografia do autor, 19/05/2012.

Ilustração 5. Buffet servido no $47^{\circ}$ Festival do Chucrute

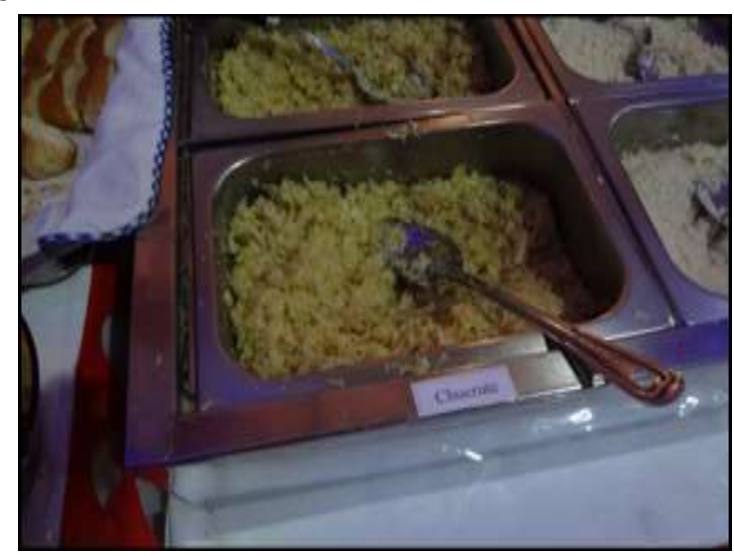

Fonte: Fotografia do autor, 19/05/2012.

Ilustração 6. Coreografia de abertura do $47^{\circ}$ Festival do Chucrute 


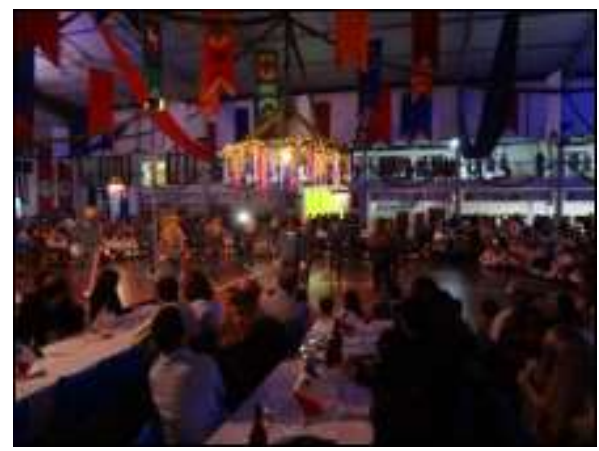

Fonte: Fotografia do autor, 19/05/2012.

Seyferth (2000, p. 147) atenta para o fato de que “(...) o relativo isolamento [dos imigrantes] (...), bem como a formação de instituições comunitárias específicas (...), deram posterior respaldo à formulação das identidades étnicas." Da mesma forma, quando os municípios colonizados por alemães ou italianos do Brasil buscam legitimar a sua identidade cultural, são estas instituições comunitárias que exercem importante função na construção discursiva e na elaboração das representações dessa identidade.

A escola, a igreja, as festas, os grupos de danças, os corais, dentre outras instituições criadas e mantidas pelos imigrantes e seus descendentes, são materializações do imaginário acerca do passado, cuja função é a de garantir a sustentação desse discurso. No Vale do Taquari, a manutenção dessas tradições se desenvolve por meio de inúmeras manifestações materiais e imateriais, dando vida a um patrimônio histórico e cultural que identifica a região como potencial cenário turístico, atraindo visitantes e investimentos nos mais diversos setores. Economia e cultura, assim, atuam de forma conjunta no desenvolvimento regional, mesmo que ambas permaneçam como esferas distintas da realidade.

Ao serem analisadas as festividades do Vale do Taquari por meio do Festival do Chucrute, identificou-se um jogo de forças dentro do próprio território. Os atores locais e regionais, ao edificarem uma determinada identidade cultural predominante, acabam por excluir outras representações, mesmo que discursivamente estas permaneçam integradas à cultura regional.

Assim, diante das tensões e lutas pela hegemonia cultural no território, o Festival do Chucrute vêm divulgando uma identidade principal, que serve de inspiração para as suas manifestações - a identidade germânica ou teuto-brasileira. No entanto, ao longo da sua existência, esse caráter passou por desconstruções, reelaborações e adaptações às diferentes épocas e lugares.

Alguns atores lutam para manter vivas essas referências, principalmente os coordenadores, os participantes mais antigos e os idealizadores do evento; aqueles cuja memória ainda está direta ou parcialmente ligada aos antepassados. Mas, para muitos, a alegria, a amizade, a festa, ou até mesmo os interesses econômicos estão acima da preocupação em "preservar" o passado e a cultura germânica.

São múltiplos saberes e vivências que se integram a estas manifestações culturais, tornando-as cenários em que não apenas uma identidade se faz visível, 
apesar da hegemonia de um determinado grupo que as realiza. Sendo assim, são manifestações híbridas. Apesar das danças, da música, dos trajes, da gastronomia e dos demais elementos estarem associados a uma determinada identidade cultural, o hibridismo se manifesta em todos os momentos de atuação dos dançarinos e do desenvolvimento da festividade.

\section{Considerações finais}

Os diversos momentos observados e analisados nesta pesquisa revelaram detalhes que a etnografia possibilita captar, mesmo que não se apreenda tudo o que acontece no cenário observado. Cabe ao pesquisador criar um aparato teórico e metodológico que o instrumentalize a se inserir nesse campo de ação, porém não se pode ignorar aquilo que os atores sociais revelam durante este processo.

Investigar as manifestações culturais que atuam na construção da identidade territorial é um importante meio de identificar, por exemplo, possibilidades de desenvolvimento regional, desde que não se imponham verdades estabelecidas e se tenha a disposição de compreender as particularidades e especificidades de um espaço que se constrói no cotidiano e cuja identidade está em permanente transformação, apesar das tentativas de homogeneização impostas pela globalização ou pela própria região.

Ao longo das suas 47 edições, o Festival do Chucrute foi incorporando atrações a sua programação, o que os atores locais planejaram que fosse exibido aos atores externos. Por isso, pode-se avaliar que as festas típicas são momentos privilegiados para a comunicação do discurso identitário que se constrói, ao longo do tempo, no e sobre o território. O público que participou do $47^{\circ}$ Festival do Chucrute, pertencente ou não ao território onde ele ocorreu, trouxe consigo elementos que interferiram na sua percepção acerca das manifestações culturais representadas durante a sua realização, bem como quem construiu a festa.

Assim, essas produções culturais atuam na construção de uma identidade territorial, reafirmando um discurso que, mesmo em movimento, estabelece verdades e cristaliza as representações acerca do Vale do Taquari. Quando se projeta o regional a partir da perspectiva territorial, é fundamental que essa produção cultural e suas respectivas identidades sejam percebida não como a essência do território, mas como um processo de lutas, negociações e escolhas que visam marcar a diferença no contexto da globalização, quando as regiões e seus territórios podem representar a resistência ou a conformação com a ordem global.

Apesar das transformações que ocorreram ao longo do tempo, as manifestações culturais do Vale do Taquari, inspiradas na identidade germânica, atuaram e permanecem produzindo representações acerca do território. No momento em que essas produções interagem com os atores locais, regionais ou de outros territórios, a diferenciação se manifesta por meio da linguagem e dos símbolos evidenciados como essência do lugar que representam.

Frente à força globalizante que desterritorializa, eis que surgem os atores do território para marcar a sua diferenciação, o seu pertencimento a uma região, a 
"identidade social sobre o espaço" (COSTA 1997, p. 39). Mesmo em projetos que evoquem o que para o território em questão é o hegemônico, isso não representa necessariamente um rompimento com o estabelecido naquele espaço, mas uma reação talvez conservadora ao externo que avança.

\section{REFERÊNCIAS}

AMARAL, Rita. As mediações culturais da festa "à brasileira". TAE - Trabalhos de Antropologia e Etnologia - Revista inter e intradisciplinar de Ciências Sociais. Sociedade Portuguesa de Antropologia e Etnologia. v. 40, n. 1-2, 2000.

BHABHA, Homi. O local da cultura. Belo Horizonte: UFMG, 2001.

CARNEIRO, Maria José. Sobre "lugar", "território" e "globalização". Revista Desenvo/vimento Social, Montes Claros, n. 2, p. 69-75, dez. 2008.

CALENDÁRIO DE EVENTOS DA SECRETARIA DO TURISMO DO ESTADO DO RIO GRANDE DO SUL - $1^{\circ}$ SEMESTRE DE 2013. Disponível em: <http://www.turismo.rs.gov.br.> Acesso em: 2 nov. 2012.

COSTA, Rogério Haesbaert. Des-territorialização e identidade: a rede "gaúcha" no nordeste. Niterói: EDUF, 1997.

ESCOSTEGUY, Ana Carolina D. Cartografias dos estudos culturais. Belo Horizonte: Autêntica, 2001.

FESTIVAL DO CHUCRUTE. Disponível em:

<http://www.festivaldochucrute.com.br>. Acesso em 3 nov. 2012

GUARINELLO, N. L. Festa, trabalho e cotidiano. In: JANCSÓ, I.; KANTOR, I. (Orgs). Festa, cultura e sociabilidade na América Portuguesa. São Paulo: Hucitec/ Edusp, 2001.

HALL, Stuart. A centralidade da cultura: notas sobre as revoluções culturais do nosso tempo. Cultura, Mídia e Educação - Educação \& Realidade. Porto Alegre, v. 22, n.2, p. 15-46, jul./dez. 1997.

A identidade cultural na pós-modernidade. Rio de Janeiro: DP\&A, 2006.

. Da Diáspora: Identidades e Mediações culturais. Belo Horizonte: UFMG; Brasília: Unesco, 2003.

HESSEL, Lothar. O Município de Estrela: história e crônica. Porto Alegre: Ed. da Universidade, UFRGS/Martins Livreiro Editor, 1983.

SCHIERHOLT, José Alfredo. Estrela: ontem e hoje. Lajeado: O autor, 2002. 
WOODWARD, Kathryn. Identidade e diferença: uma introdução teórica e conceitual. In: SILVA, Tomaz Tadeu (org.). Identidade e Diferença: a perspectiva dos estudos culturais. Petrópolis, RJ: Vozes, 2000.

FONTES PRIMÁRIAS:

Jornal Folha de Estrela. Suplemento especial sobre os 40 anos do Festival do Chucrute. Estrela, maio de 2005.

Entrevistas com integrantes dos Grupos de Danças Folclóricas Alemãs de Estrela e do $47^{\circ}$ Festival do Chucrute.

Submetido em 30/06/2013

Aprovado em 01/12/2014

\section{Sobre os autores}

\section{Cristiano Nicolini}

Mestre em Desenvolvimento Regional pela UNISC - Universidade de Santa Cruz do Sul, Brasil. Doutorando em Ciências da Comunicação - Universidade da Beira Interior, Portugal.

Endereço: Rua XV de Novembro, 154, Ap 203, Centro. 95880000 - Estrela -RS - Brasil.

E-mail: cristiano782006@hotmail.com.

\section{Ângela Cristina Trevisan Felippi}

Doutora em Comunicação Social pela PUCRS - Pontifícia Universidade Católica do Rio Grande do Sul. Professora pesquisadora do Programa de Pós-graduação em Desenvolvimento Regional da UNISC - Universidade de Santa Cruz do Sul, Brasil.

Endereço: Av. Independência, 2293, Universitário. 96815-900 - Santa Cruz do Sul, RS - Brasil.

E-mail: angelafe@unisc.br. 